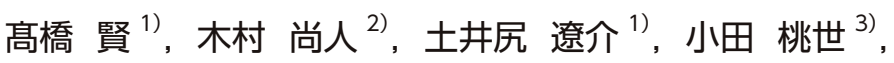 \\ 横沢 路子 ${ }^{2)}$, 菅原 孝行 ${ }^{2)}$, 高橋 弘明 $^{1)}$, 菊池 貴彦 ${ }^{1)}$ \\ 1) 岩手県立中央病院脳神経内科 \\ 2) 岩手県立中央病院脳神経外科 \\ 3) 岩手県立中央病院リハビリテーション科
}

\title{
A case wherein transoral carotid ultrasonography was performed before and after stent-assisted coil embolization for a pseudoaneurysm of the cervical internal carotid artery
}

\author{
Ken TAKAHASHI ${ }^{1)}$, Naoto KIMURA ${ }^{2)}$, Ryosuke DOIJIRI ${ }^{1)}$, Momoyo ODA $^{3)}$, \\ Michiko YOKOSAWA $^{2)}$, Takayuki SUGAWARA ${ }^{2)}$, Hiroaki TAKAHASHI ${ }^{1)}$, Takahiko KIKUCHI $^{1)}$ \\ 1) Department of Neurology, Iwate Prefectural Central Hospital \\ 2) Department of Neurosurgery, Iwate Prefectural Central Hospital \\ 3) Department of Rehabilitation, Iwate Prefectural Central Hospital
}

An 80-year-old woman was diagnosed with acute middle cerebral artery occlusion and underwent mechanical thrombectomy (MT). The iatrogenic arterial dissection formed in the cervical internal carotid artery during MT. This was observed because there was no stenosis or extravasation. On follow-up, a pseudoaneurysm was observed; therefore, stent-assisted coil embolization was performed to prevent rupture and thromboembolism. Although computed tomography angiography was not useful for post-treatment evaluation due to metal artifacts, transoral carotid ultrasonography (TOCU) confirmed that the lumen of the stent was well delineated and there was no blood flow within the coil-filled mass. TOCU is therefore useful in the diagnosis and post-treatment evaluation of pseudoaneurysms.

Keywords: transoral carotid ultrasonography, mechanical thrombectomy, iatrogenic pseudoaneurysm, stentassisted coil embolization

(Received February 4, 2021; Accepted March 11, 2021)

はじめに

急性期脳主幹動脈閉塞症に対する血栓回収療法は標準 の治療となった，発症自体はまれではあるが，合併症と して頸部内頸動脈解離を発症する頻度が従来の脳血管内 治療よりも上昇した，今回，血栓回収療法時に形成され た頸部内頸動脈の仮性動脈瘤に対するステント併用コイ ル塞栓術前後評価に経口腔頸動脈超音波検査（transoral carotid ultrasonography：TOCU）が有用であった症例
を経験したので報告する。

本症例で使用した脳動脈瘤コイル塞栓補助ステント （LVIS Blue，テルモ，東京）は保険適用外使用であり， われわれの施設では倫理委員会の承認を得て使用した (承認 No.2182).

また，本症例報告に関しては患者の同意を得ている.

症例

患者：80 歳, 女性. 

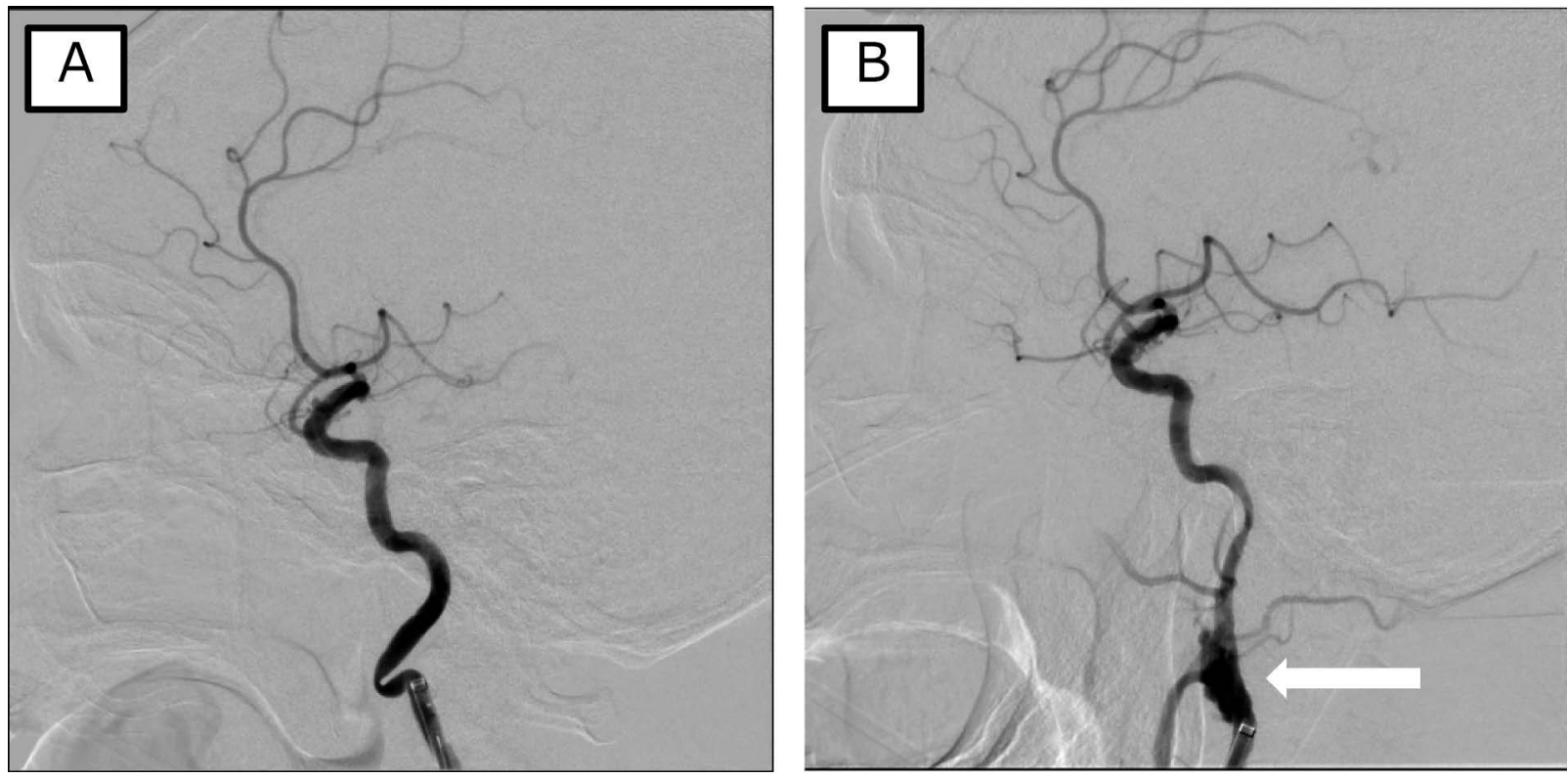

Fig. 1 Lateral view of the right internal carotid arteriography (ICAG) during thrombectomy

A: Pre ICAG showed a 9Fr balloon guiding catheter placed in a tortuous internal carotid artery (ICA).

B: Post ICAG showed a dissection at high cervical ICA (arrow).

主訴：左無視, 左片麻痺.

既往歴：発作性心房細動を伴う洞不全症候群（ペース メーカー植え达み術施行済み), 高血圧症, 2 型糖尿病, 脂質異常症.

嗜好歴：飲酒歴なし，喫煙歴なし。

現病歴：起床時より歩行に介助を要するようになり，前 医を受診した。左半身の麻痺を認め脳卒中が疑われ，最 終未発症確認から 12 時間, 起床から 140 分で当院へ搬 送された。

来院時現症：身長 $144 \mathrm{~cm}$, 体重 $41 \mathrm{~kg}$, body mass index $19.7 \mathrm{~kg} / \mathrm{m}^{2}$ ，血圧 $207 / 86 \mathrm{mmHg}$ ，脈拍 $65 /$ 分 - 整，体温 $36.0^{\circ} \mathrm{C}$ ，胸部聴診で異常なし．意識レベル Japan Coma Scale II-10, 左半側空間無視, 右共同偏視, 顔面を含む 左片麻痺を認めた。 National Institutes of Health Stroke Scale (NIHSS) スコア 19 点.

検査所見：血液検査では血算に異常なし，凝固系では D-dimer $1.18 \mu \mathrm{g} / \mathrm{ml}$ と基準值を上回っていた．生化学で は LDL-C $112.0 \mathrm{mg} / \mathrm{dl}$, HDL-C 56.7mg/dl, HbA1c 6.6\% だった。胸部 X 線写真（臥位）では心胸郭比 $67 \%, 12$ 誘導心電図は洞調律であった。頭部 CT では早期虚血性 変化は認められず, Alberta Stroke Program Early CT Score (ASPECTS) 10 点であった.

入院後経過：発作性心房細動の既往があり心原性脳塞栓 症を疑い，脳血管撮影を行った。右内頸動脈造影で右中 大脳動脈 M2 superior division 近位閉塞を認めたため血 栓回収療法を行った。9Fr Optimo（東海メディカルプ ロダクツ, 愛知）を右内頸動脈 cervical portion へ誘導, Penumbra 5MAX ACE60 reperfusion catheter $132 \mathrm{~cm}$ (Penumbra, Alameda, CA, USA), Trevo Pro18 Micro- catheter $2.4 \mathrm{Fr} / 150 \mathrm{~cm}$ (Stryker, Kalamazoo, MI, USA), CHIKAI black 18 （朝日インテック，愛知）の組み合わ せで閉塞部を通過，Trevo Pro18 Microcatheter を遠位へ 誘導し Trevo XP ProVue Retriever 4mm × 20mm (Stryker) を展開し回収した。確認造影で右 M2 の再開通は得ら れず，また右頸部内頸動脈に動脈解離を認めた（Fig.1）. Optimo を慎重に解離部分を通過させてから同様の手技 を行ったが再開通は得られなかった。造影で解離部分に 悪化がないことを確認し 2 パスで血管内治療を終了し た。脳梗塞に対して内科治療を行い，神経症状に著明な 悪化なく経過した。術後に右頸部皮下出血を認めたが， 二次予防の抗血栓薬としてエドキサバン $30 \mathrm{mg} /$ 日を導 入後に出血の拡大なく経過した。第 13 病日の頭頸部 CT angiography（CTA）で右頸部内頸動脈に仮性動脈 瘤の形成を認めた $(14.3 \times 7.7 \times 7.0 \mathrm{~mm}$, ネック $7.0 \mathrm{~mm})$. TOCU (LOGIQ P6, GEヘルスケア・ジャ パン，東京，8C 探触子使用）では内頸動脈分岐から約 $3 \mathrm{~cm}$ 遠位の内頸動脈前壁に瘤状の拡張を認め $(14.2 \times$ $6.2 \mathrm{~mm}$ ，ネック $7.5 \mathrm{~mm})$, カラードプラにて同部位への 血流が確認できた（Fig.2A）。破裂や血栓塞栓症予防の ため血管内治療を行った。右内頸動脈起始部に $8 \mathrm{Fr}$ FlowGate2（Stryker）を誘導し，ステント展開のため Headway21 ST (テルモ) を右頸部内頸動脈遠位へ誘導, コイル塞栓のため SL-10 J shape（Stryker）を瘤内へ誘 導した. LVIS Blue $4.5 \mathrm{~mm} \times 32 \mathrm{~mm}$ （テルモ）を用い たステント併用コイル塞栓術（jailing technique, 計 8 本, $109 \mathrm{~cm}$ のコイル挿入）によりわずかな neck remnant の 状態で血管内治療を終了した（Fig.3A〜C).コイル塞 栓術後の頭頸部 CTA はコイルとステントの金属アーチ 

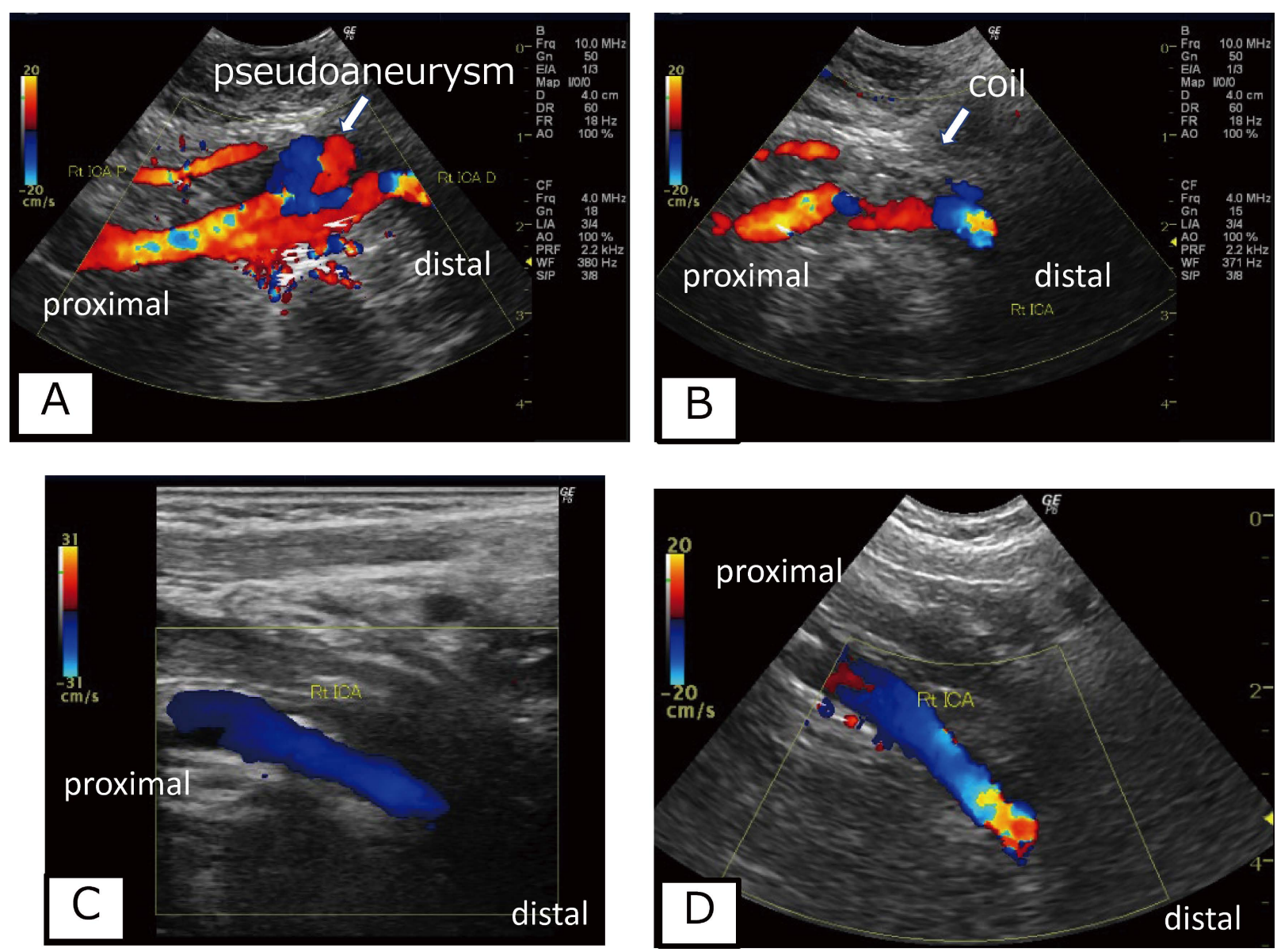

Fig. 2 Transoral carotid ultrasonography (TOCU)

A: Pre TOCU Doppler-color image revealed a pseudoaneurysm.

B: Post TOCU Doppler-color image revealed occlusion of the pseudoaneurysm and patency of the stented ICA.

C: Carotid duplex sonography using a linear probe can show up to the internal carotid artery at the level of the C4 vertebra.

D: Carotid duplex sonography using a micro convex probe can show up to the internal carotid artery at the level of the C3 vertebra.

ファクトのため血管内腔開存や塞栓状態の評価は困難で あるが (Fig.3D, E), TOCUでは金属アーチファクト はなくステント内腔が良好に描出され，瘤内に流入する 血流がないことを確認可能であった（Fig.2B）。これ以 降は脳梗塞の再発や出血性合併症なく経過し, 第 48 病 日に NIHSS 14 点, modified Rankin Scale grade 5 で回 復期リハビリテーション病院へ転院となった。

\section{考察}

2014 年から 2015 年にかけて, 急性期脳主幹動脈閉 塞症に対する血栓回収療法の有効性を示す複数のランダ 厶化比較試験が報告された。それらのメ夕解析 (HERMES collaboration) にて ${ }^{1}$ ， 年齢や重症度にかか わらず前方循環主幹動脈近位部閉塞に対しては血栓回収 療法の有効性と安全性が示され，適応を満たす症例に対 しては施行すべき治療となった。

従来，脳血管造影や脳血管内治療の合併症としての動 脈解離はそれぞれ $0.25 〜 0.35 \%, 0.26 〜 0.53 \%$ と，ま れであることが報告されている ${ }^{2,3)}$. 一方, 血栓回収療 法のランダム化比較試験において, 治療に伴う動脈解離
の頻度は $0.6 〜 3.9 \%$ と報告されており，従来の脳血管 内治療よりも高くなっている ${ }^{4-7)}$. Goeggel Simonetti ら は, 機械的血栓回収療法で 2\%の症例に医原性動脈解離 が発生したと報告している，解離の形成部位は，頭蓋外 頸部内頸動脈が 78\%であった。 ステント抜去時ではな く, ガイディングカテーテルから血管閉塞部位へアクセ スする際に, 屈曲や蛇行している頸部内頸動脈を通過す るデバイスが引き金となり解離が発生していた ${ }^{8)}$. 本症 例ではガイディングカテーテルから吸引カテーテル，マ イクロカテーテルを誘導する際, 蛇行した頸部内頸動脈 に吸引カテーテルが先行して誘導されたため解離が形成 されたと考えられた。 ガイディングカテーテルは内頸動 脈起始部より遠位に留置されるため, 解離が形成された 際は通常の頸動脈超音波検査では評価困難な場合が多 い.

TOCUは 1998 年に Yasaka らによって考案された, 体腔用探触子を口腔内に挿入し，頭蓋外内頸動脈遠位部 を観察する方法である ${ }^{9}$. 2013 年に姉川らが，より汎 用性の高いマイクロコンベックス型探触子でも TOCU と同等の画像情報が得られる modified TOCUを考案し 

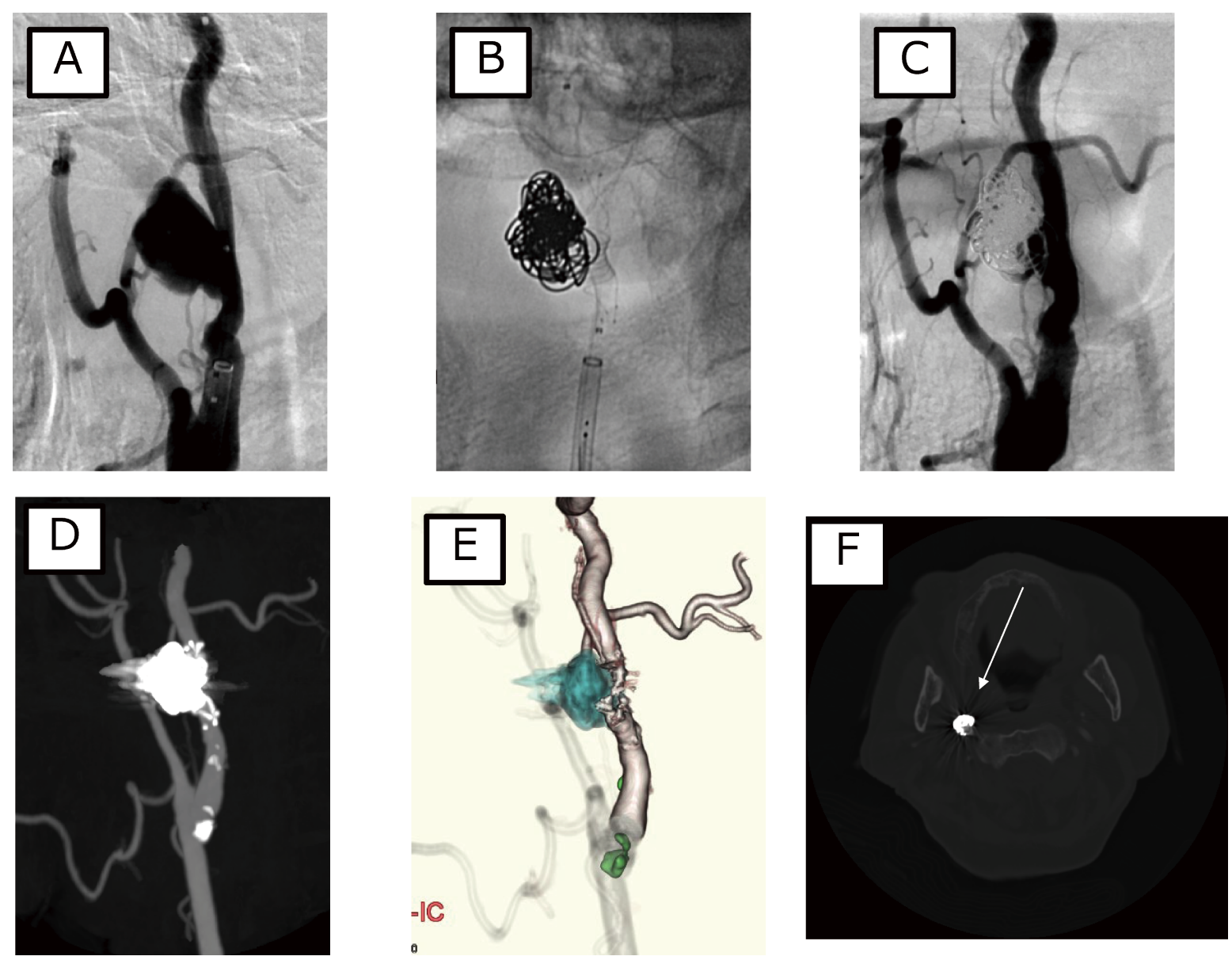

Fig. 3 Right carotid artery image pre and post stent-assisted coil embolization

A: Pre common carotid artery angiography (CCAG) shows a pseudoaneurysm at the cervical ICA.

B, C: Post CCAG revealed occlusion of the pseudoaneurysm and patency of the stented ICA.

D, E: 3D-CT angiography was not able to reveal patency of stented ICA due to metal artifacts.

$\mathrm{F}$ : The coil mass is in front of the ICA where the echo beam passes through (arrow).

た ${ }^{10)}$ 。当院では超音波画像診断装置は GE 社製 LOGIQ P6，マイクロコンベックス型探触子（8C）を用いて TOCUを行っている。探触子の先端に検査用ゼリーを 塗り, 医療用コンドームで探触子をカバーし検査を行う. 本症例でも体表アプローチの頸動脈超音波検査では, リ ニア型探触子（9L）でC4椎体上縁レベル（Fig.2C）, マイクロコンベックス型探触子（8C）で C3 椎体レベ ル（Fig.2D）の内頸動脈までしか描出されず，病巣のあ る C2 椎体下縁〜 C3 椎体上縁レベルの内頸動脈描出は 困難だったが，TOCUでは描出可能であった。通常の TOCU では咽頭の局所麻酔は不要である。本症例でも 咽頭反射の誘発はなく, 繰り返し検査可能であった。

頸動脈解離により形成された仮性動脈瘤の治療方針に 一定の見解はない. Daou らは370 例の特発性または外 傷によって形成された頸動脈または椎骨動脈の解離症例 のうち, 仮性動脈瘤形成を認めた 112 症例 120 動脈瘤 の報告をしている. $53.4 \%$ で頸部内頸動脈に仮性動脈瘤 が形成されており，経過観察で治癒したのは $30.2 \%$, 56.0\%で変化なし， $13.8 \%$ で増大した， $10 \mathrm{~mm}$ より超え る瘤の増大や瘤に伴う症状が出現している症例は治療介
入されている。治療法はステント留置, コイル塞栓, flow diversion, クリップが行われていた。無症候で瘤の 増大がなければ内科治療で経過観察が選択されるが ${ }^{11)}$, 本症例のように瘤が増大しサイズが大きい場合は治療介 入が望ましい.

脳血管内治療の領域において TOCU は術前後評価, 合併症評価の手段としてとして有用である。体表からの アプローチによる頸動脈超音波検査では，描出困難な高 位頸部内頸動脈に形成された解離性動脈瘤に対して行わ れた頸動脈ステント留置術後のステント開存と動脈瘤へ の血流有無の詳細な評価が可能である ${ }^{12)}$. 脳血管内治 療中に, ガイディングカテーテルを留置した高位頸部内 頸動脈に形成された解離からの extravasation と偽腔の評 価のため, 繰り返し脳血管造影を行わなくとも TOCU で評価できる点がメリットである ${ }^{13)}$.

本症例で特筆すべき点は，エコービーム直上にコイル 塊があっても（Fig.3F）血管内腔の評価, 瘤内への血流 有無が詳細にわかる点である，仮性動脈瘤への治療適応 は瘤の増大の有無や大きさで判定される。頻繁な脳血管 造影や造影 CTよりも TOCUは低侵襲と考えられる. 
本症例のようにペースメーカー植え込みなどの理由で MRA 撮像困難な症例に対しては特に有用な評価法であ る。コイル塞栓が行われた場合は，金属アーチファクト のためCTや MRI では術後評価は困難となるが, TOCUであれば詳細な評価が可能である。血栓回収療 法の標準化とともに，今後は医原性動脈解離を経験する 機会が増加すると考えられる。TOCU は経過観察と治 療後の評価のためきわめて有用である.

\section{結語}

脳血管内治療の合併症として形成された仮性動脈瘤に 対するステント併用コイル塞栓術の適応判定, 治療後の 評価にTOCUは有用である.

利益相反：著者全員が本論文に関して開示すべき利益 相反はない。

\section{- 文献}

1) Goyal M, Menon BK, van Zwam WH, et al.: Endovascular thrombectomy after large-vessel ischaemic stroke: a metaanalysis of individual patient data from five randomised trials. Lancet 2016; 387: 1723-1731.

2) Groves AP, Kansagra AP, Cross DT, 3rd, et al.: Acute management and outcomes of iatrogenic dissections during cerebral angiography. J Neurointerv Surg 2017; 9: 499-501.

3) Paramasivam $S$, Leesch W, Fifi J, et al.: Iatrogenic dissection during neurointerventional procedures: a retrospective analysis. J Neurointerv Surg 2012; 4: 331-335.

4) Bracard S, Ducrocq X, Mas JL, et al.: Mechanical thrombectomy after intravenous alteplase versus alteplase alone after stroke (THRACE): a randomised controlled trial. Lancet Neurol 2016; 15: 1138-1147.

5) Jovin TG, Chamorro A, Cobo E, et al.: Thrombectomy within 8 hours after symptom onset in ischemic stroke. N Engl J Med 2015; 372: 2296-2306.

6) Goyal M, Demchuk AM, Menon BK, et al.: Randomized assessment of rapid endovascular treatment of ischemic stroke. N Engl J Med 2015; 372: 1019-1030.

7) Berkhemer OA, Fransen PS, Beumer D, et al.: A randomized trial of intraarterial treatment for acute ischemic stroke. $\mathrm{N}$ Engl J Med 2015; 372: 11-20.

8) Goeggel Simonetti B, Hulliger J, Mathier E, et al.: Iatrogenic Vessel Dissection in Endovascular Treatment of Acute Ischemic Stroke. Clin Neuroradiol 2019; 29: 143-151.

9) Yasaka M, Kimura K, Otsubo $R$, et al.: Transoral carotid ultrasonography. Stroke 1998; 29: 1383-1388.

10）姉川敬裕，福田賢治，甲斐久史，他：マイクロコンベックス 型探触子を用いた経口腔頸部血管超音波検查法 (modified TOCU). 脳卒中 2013; 35: 1-4.

11) Daou B, Hammer C, Chalouhi $\mathrm{N}$, et al.: Dissecting pseudoaneurysms: predictors of symptom occurrence, enlargement, clinical outcome, and treatment. J Neurosurg 2016; 125: 936-942.

12）萩原悠太, 吉江智秀, 徳山承明, 他：頭蓋外内頸動脈解離に 対する頸動脈ステント留置術前後の評価に経口腔頸動脈超音 波検查（transoral carotid ultrasonography）が有用であった 1 例. Neurosonology 2016; 29: 185-190.

13) Itabashi R, Furui E, Suzuki I, et al.: Iatrogenic Extravasation and Extracranial ICA Dissection during Neurointervention Evaluated by Transoral Carotid Ultrasonography: Case Report. J Vasc Interv Neurol 2018; 10: 66-67. 